\title{
Regional tenders on biosimilars in Italy: potentially competitive?
}

\author{
Alessandro Curto, MSSc; Katelijne Van de Vooren, MSc; Roberta Lo Muto, MSc; Silvy Duranti, MBA; Professor Livio \\ Garattini
}

\begin{abstract}
Introduction: Health care in Italy is mainly delivered through the country's National Health Service (NHS), a public service funded by general taxation. The system is highly decentralized and each one of the 20 Regional Health Authorities (RHAs) can establish a central organization for purchasing goods and services. Drugs are purchased via a tender process, which is similar to an auction; price quotations are invited from drug manufacturers before a decision is made on the preferred manufacturer.

There are three off-patent biologicals (somatropin, epoetin, filgrastim) for which biosimilars are already available in Italy. Here we present and analyse the various regional tenders referring to the three off-patent biologicals, in order to assess the potential level of competition.

Methods: To collect detailed information, we conducted a web-based analysis up to December 2012. Only eight RHAs have held tenders that include biosimilars. We analysed the main characteristics of these tenders, focusing in particular on the base quantities and base prices reported in the bids for each lot including one of the three off-patent biologicals considered. We then estimated the number of potential competitors for each.

Results: From the 24 tenders analysed, we retrieved 191 lots referring to the three off-patent biologicals. The prevailing practice in Italy is to launch very large tenders split into many lots. The need to continue a therapy that had already started, according to the current non-substitution policy, might explain the substantial number of lots restricted to original agents (around 30\%). Nevertheless, the lack of potential competition, particularly for somatropin seems to be extensive and hard to justify.

Conclusion: In theory, the economic literature suggests that worthwhile savings can be achieved from public tenders. However, in practice this depends on how the bidders (manufacturers) and buyers (regional authorities) behave in the market.
\end{abstract}

Keywords: Biosimilars, competition, Italy, regions, tenders

\section{Introduction}

Italy is the third largest national pharmaceutical market in Europe [1]. Health care is mainly delivered through the country's National Health Service (NHS), a public service funded by general taxation, which provides universal coverage and comprehensive health care free at the point of delivery. The system is highly decentralized and 20 Regional Health Authorities (RHSs) are responsible for planning healthcare services and allocating financial resources. In principle, local autonomy implies stronger financial accountability, which leads regions to develop different economic strategies. To control and rationalize expenditure, each Italian RHA can establish a central organization for purchasing goods and services [2]. The regions differ widely in size, with residential populations ranging from around 130,000 (Valle d'Aosta) to 10,000,000 inhabitants (Lombardy), see Figure 1 [3]. Eight large regions are divided into 'Vast Areas' (VA), although only two of them (Emilia-Romagna and Tuscany) have appointed these organizations for drug purchasing.

Drugs receiving authorization from EMA can be marketed in Italy only after the Italian Agency for Medicines (AIFA; Agenzia Italiana del Farmaco) has decided on their reimbursability and negotiated a price on behalf of the NHS. Since 2001, a reference price system has existed, although limited to off-patent drugs containing the same substance. AIFA issues a monthly 'Transparency List' (TL) of off-patent products considered equivalent and their reference prices.
The Decree Law 219/06, based on the European Directive 2001/83/EC and its subsequent modifications, includes the only Italian specific regulation on biosimilars. AIFA takes the position of EMA, stating that biosimilars cannot be considered identical, because of their complex intrinsic character and manufacturing process [4]. Therefore, the pharmacist is not allowed to substitute automatically, unlike the situation for generics. Consequently, biosimilars are not included in the TL and the decision to prescribe either the original agent or the biosimilar is entirely handled by physicians, particularly hospital consultants in the case of the three off-patent biologicals (somatropin, epoetin, filgrastim) for which biosimilars are available in Italy so far.

The current global economic crisis has hit Italy harder than some other major EU countries and the national and regional governments have cut budgets in all areas to save money [5], including health care. With a tighter budget and accountability for overspending on hospital drugs, RHAs are expected to exploit to the utmost the potential savings induced by widespread consumption of biosimilars $[6,7]$. Furthermore, the forthcoming patent expiry of some very expensive biologicals (like bevacizumab, cetuximab and trastuzumab) [8] makes it even more important to enhance price competition. Here we present and analyse the various tenders referring to the three off-patent biologicals conducted so far at regional and VA level, in order to assess the potential level of competition. During the

Author for correspondence: Professor Livio Garattini, Centre for Health Economics (CESAV), Istituto di Ricerche Farmacologiche Mario Negri (IRCCS), IT-24020 Ranica (BG), Italy

Submitted: 4 April 2013; Revised: 27 May 2013; Accepted: 11 June 2013; published online first: 25 June 2013 
Figure 1: Population of Italian regions* (2012)

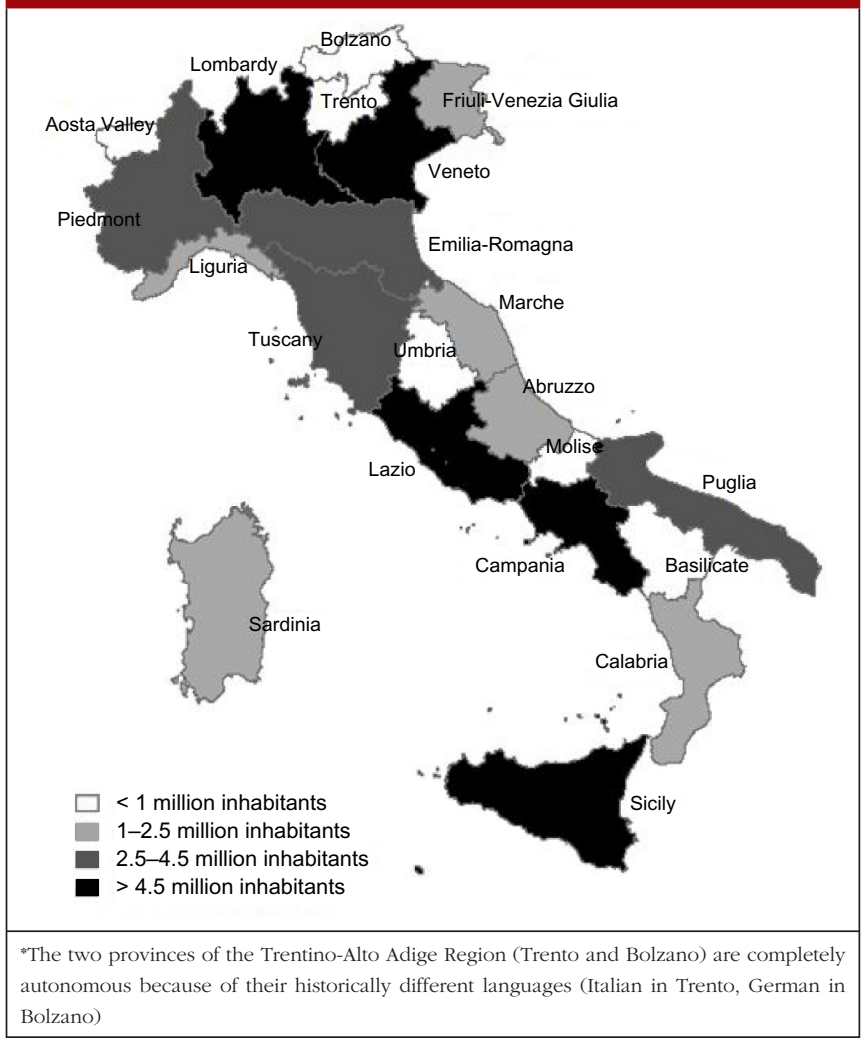

tender process, which is similar to an auction, price quotations are invited from drug manufacturers before a decision is made on the preferred manufacturer. The aim is to provide quality drugs at the lowest possible cost when needed.

\section{Italian market situation}

Eight of the 12 biosimilars approved by EMA are licensed in Italy, covering three different biologicals (somatropin, epoetin, filgrastim) marketed by four companies. Table 1 gives a simplified picture of all the products and dosages reimbursed in Italy for each of the three off-patent biologicals (by anatomical therapeutic chemical code). The official prices of all these products have kept steady during the study period.

Although all regions have established a central purchasing authority, only eight RHAs have held public tenders to procure biosimilars for their hospitals so far, see Table 2. Twenty-four tenders including the three off-patent biologicals took place during the study period. The total number of lots in each tender was very high on average (811) since most bids referred to a huge number of drugs. The procedure was always open to all interested companies.

\section{Methods}

To collect detailed information on regional (and VA) biosimilar tenders, we conducted a web-based analysis up to December 2012. We divided our team into two project groups. Since it is now mandatory in Italy to publish regional tenders in the European Official Bulletin, the first group (VK and DS) started from this [9], searching by: i) product group and classification (using the Common Procurement Vocabulary code, CPV); ii) location (using the geographical coding system for nations and regions, NUTS2); and iii) main activity (focusing on 'health'). The second group (CA and LMR) analysed separately the information on the Regional Central Purchasing Authorities' websites, as a 'secondary source' for validation.

We analysed the main characteristics of tenders, focusing in particular on the base quantities and base prices reported in the bids for each lot including one of the three off-patent biologicals considered. According to the type of lot, we then estimated the number of potential competitors for each. A lot was classified as 'simple' when it referred to only one dosage and 'composite' for more than one. Finally, we examined the correlation between base price, base quantity and the time trend of tenders.

To complete background information and discuss the formulation and results of public procurement in their regions, we conducted semi-structured interviews with the pharmaceutical managers of three of the eight RHAs, which held tenders that included biosimilars.

\section{Results}

From the 24 tenders analysed, we retrieved 191 lots referring to the three off-patent biologicals; the lowest price/best offer was always the criterion for awarding the tender. Table 3 shows the main information on lots by region. Figure 2 shows the correlations by lot between base price with base quantity and with time. Here below we summarize the main results for each of the three biologicals ordered according to their market launch.

\section{1) Somatropin}

All the lots were simple (related to a single dosage) and around $40 \%$ concerned only one potential competitor, amounting to $85 \%$ of the total volumes tendered. Correlation between base price and base quantity or time was negligible (the line represents regression analysis). Unlike the two other biologicals, there were no lots in which the original agent competed with biosimilars.

\section{2) Epoetin}

Epoetin was the only off-patent biological for which we found composite lots, i.e. more than one dosage. Ten out of 51 lots were limited to the original agent and 11 to biosimilars only. The volumes referring to just one competitor amounted to around $20 \%$ of the total tendered. We found only negligible correlations between base price and base quantity or time for this biological.

\section{3) Filgrastim}

All the lots were simple, i.e. related to a single dosage. Around one third were limited to a single product (mainly the original agent), preventing potential competition on $4 \%$ of the total volumes put under tender. Half the lots were open to all five potential competitors, in theory allowing maximum competition according to the current market situation. We found a moderately negative relation between base price and base quantity and base price with time. 


\section{Table 1: Products and dosages of the three off-patent biologicals licensed in Italy}

a) Somatropin (ATC H01AC01)

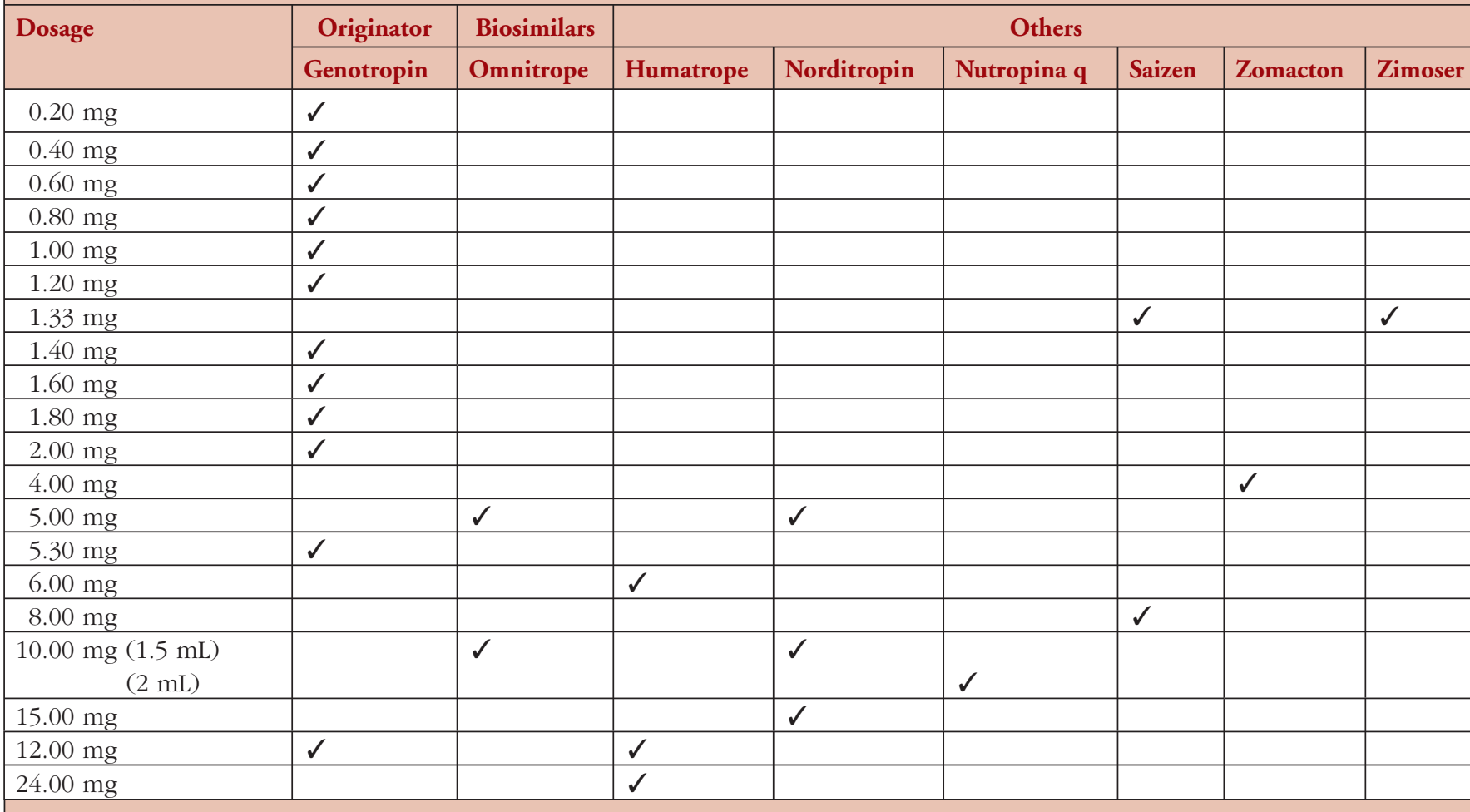

b) Epoetin (ATC B03 $\times$ A01)

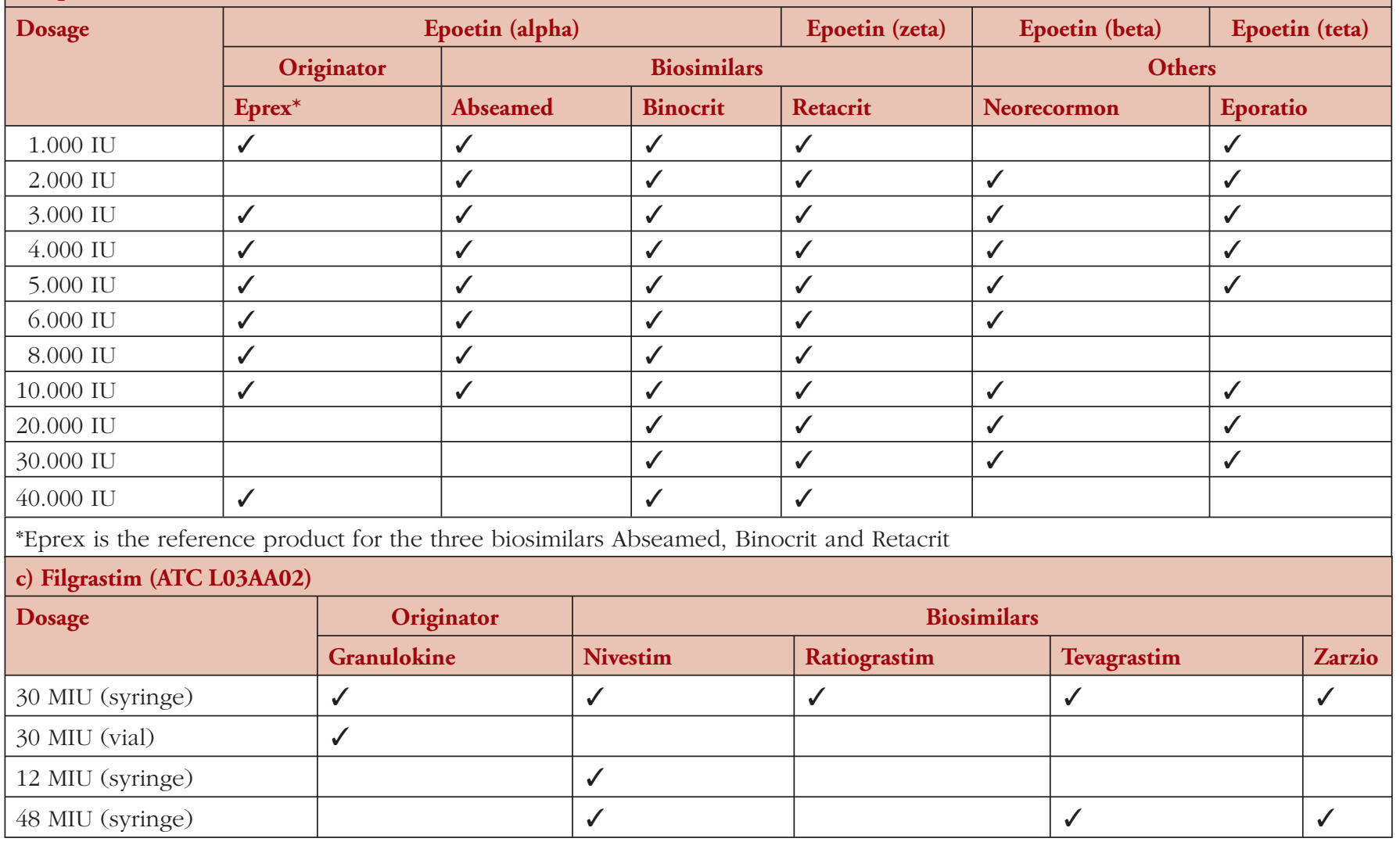




\section{Table 2: Main characteristics of regional (and VA) tenders including the three off-patent biologicals}

\begin{tabular}{|c|c|c|c|c|c|c|}
\hline Regions/Areas & Regions & Number of tenders & Mean number of lots & \multicolumn{3}{|c|}{ Lots including off-patent biologicals } \\
\hline Lombardy & & 2 & 354 & 17 & 8 & 1 \\
\hline Friuli-Venezia Giulia & & 7 & 593 & 43 & 11 & 5 \\
\hline Veneto & & 3 & 556 & 10 & 4 & 1 \\
\hline Tuscany & & 4 & 1,264 & 18 & 22 & 5 \\
\hline Campania & & 3 & 771 & 14 & 1 & 2 \\
\hline Basilicata & & 1 & 2,272 & 2 & & \\
\hline Total & 8 & 24 & 811 & 124 & 51 & 16 \\
\hline
\end{tabular}

\section{Table 3: Main variables of the lots including the three off-patent biologicals}

a) Somatropin (124 lots)

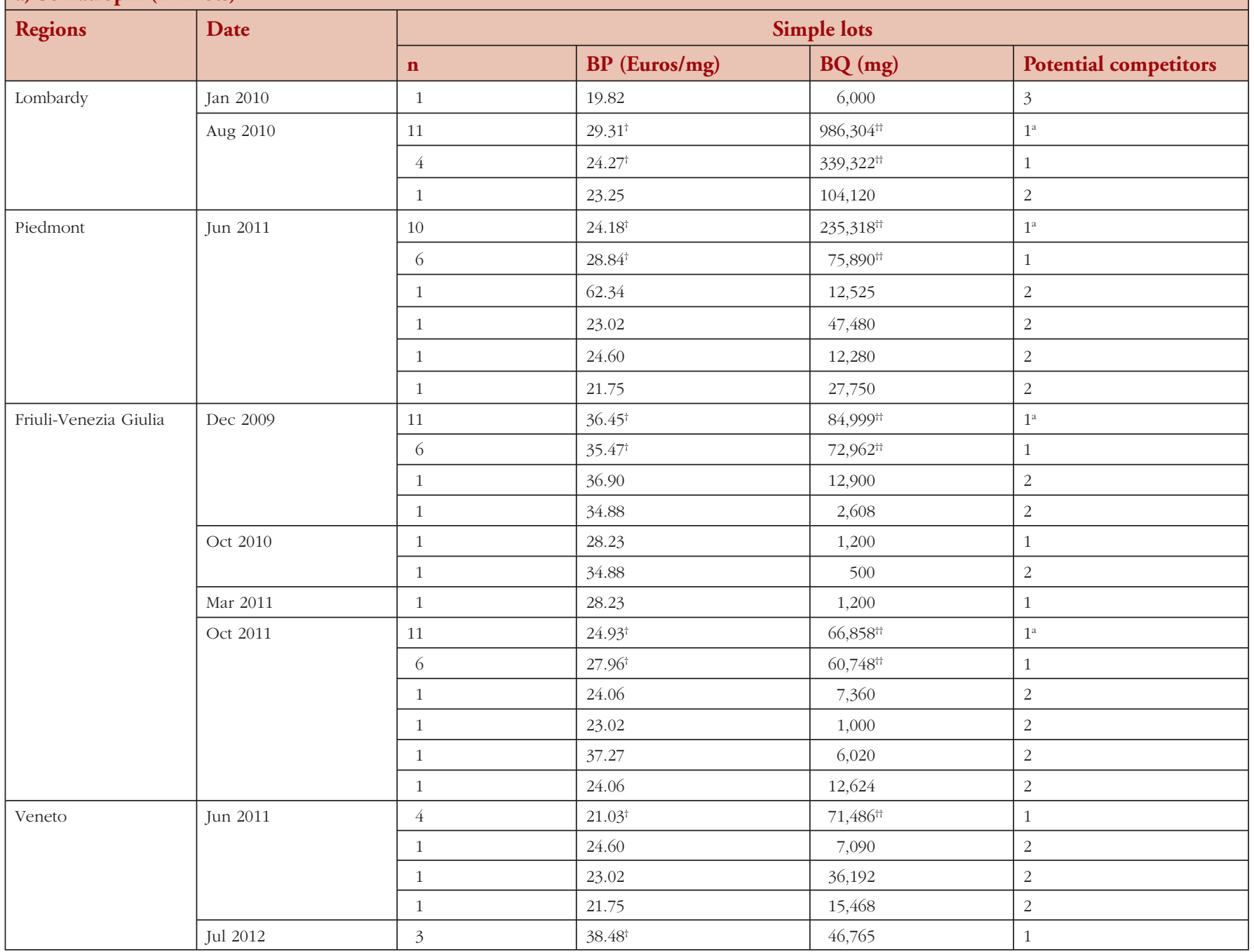

(Continued) 
Table 3: Main variables of the lots including the three off-patent biologicals (Continued)

\begin{tabular}{|c|c|c|c|c|c|}
\hline \multirow[t]{2}{*}{ Regions } & \multirow[t]{2}{*}{ Date } & \multicolumn{4}{|c|}{ Simple lots } \\
\hline & & $\mathbf{n}$ & BP (Euros/mg) & BQ (mg) & Potential competitors \\
\hline \multirow[t]{4}{*}{ Tuscany } & \multirow[t]{4}{*}{ Mar 2011} & 10 & $36.19^{\dagger}$ & $56,064^{+1}$ & $1^{\mathrm{a}}$ \\
\hline & & 1 & 37.50 & 3,489 & 2 \\
\hline & & 1 & 22.79 & 9,930 & 2 \\
\hline & & 1 & 21.87 & 3,368 & 3 \\
\hline Basilicata & Sep 2010 & 1 & 24.99 & 60 & 2 \\
\hline \multirow[t]{3}{*}{ Campania } & \multirow[t]{3}{*}{ Dec 2011} & 7 & $23.82^{\dagger}$ & $192,569^{\text {tt }}$ & $1^{\mathrm{a}}$ \\
\hline & & 2 & $14.70^{\dagger}$ & $101,484^{\mathrm{tt}}$ & $1^{\mathrm{b}}$ \\
\hline & & 5 & $20.27^{\dagger}$ & $99,905^{\text {th }}$ & 1 \\
\hline Total & & 124 & & $2,851,206$ & $1.12^{\mathrm{c}}$ \\
\hline
\end{tabular}

b) Epoetin (51 lots)

\begin{tabular}{|c|c|c|c|c|c|c|c|}
\hline Regions & Date & \multicolumn{3}{|c|}{ Simple lots } & \multicolumn{3}{|c|}{ Composite lots } \\
\hline \multirow{5}{*}{ Lombardy } & \multirow{5}{*}{ Aug 2010} & 0.0047 & $14,938,000$ & 1 & & & \\
\hline & & 0.0047 & $14,226,000$ & 3 & & & \\
\hline & & 0.0047 & $109,212,000$ & 4 & & & \\
\hline & & 0.0047 & $39,312,000$ & 4 & & & \\
\hline & & 0.0047 & $20,392,000$ & 4 & & & \\
\hline Piedmont & Jun 2011 & & & & 0.0085 & $2,855,296,242$ & 4 \\
\hline \multirow[t]{2}{*}{ Emilia-Romagna } & \multirow[t]{2}{*}{ Feb 2009} & & & & 0.0046 & $87,926,000$ & 5 \\
\hline & & & & & 0.0046 & $1,846,446,000$ & 5 \\
\hline \multirow{9}{*}{ Friuli-Venezia Giulia } & \multirow{5}{*}{ Dec 2009} & 0.0150 & $151,360,000$ & $1^{\mathrm{a}}$ & & & \\
\hline & & 0.0104 & $445,200,000$ & $1^{\mathrm{a}}$ & & & \\
\hline & & 0.0150 & $1,750,000$ & $1^{\mathrm{a}}$ & & & \\
\hline & & 0.0150 & $43,860,000$ & $1^{\mathrm{a}}$ & & & \\
\hline & & 0.0150 & $32,000,000$ & $1^{\mathrm{a}}$ & & & \\
\hline & \multirow[t]{2}{*}{ Apr 2010} & & & & 0.0160 & $170,000,000$ & $1^{\mathrm{a}}$ \\
\hline & & & & & 0.0113 & $30,000,000$ & 3 \\
\hline & \multirow[t]{2}{*}{ Oct 2011} & & & & 0.0032 & $456,011,000$ & 4 \\
\hline & & & & & 0.0032 & $91,060,000$ & 4 \\
\hline Veneto & Jun 2011 & 0.0028 & $1,270,886,400$ & 4 & & & \\
\hline Tuscany & Aug 2008 & 0.0113 & $20,020,000$ & $3^{b}$ & & & \\
\hline
\end{tabular}




\section{Table 3: Main variables of the lots including the three off-patent biologicals (Continued)}

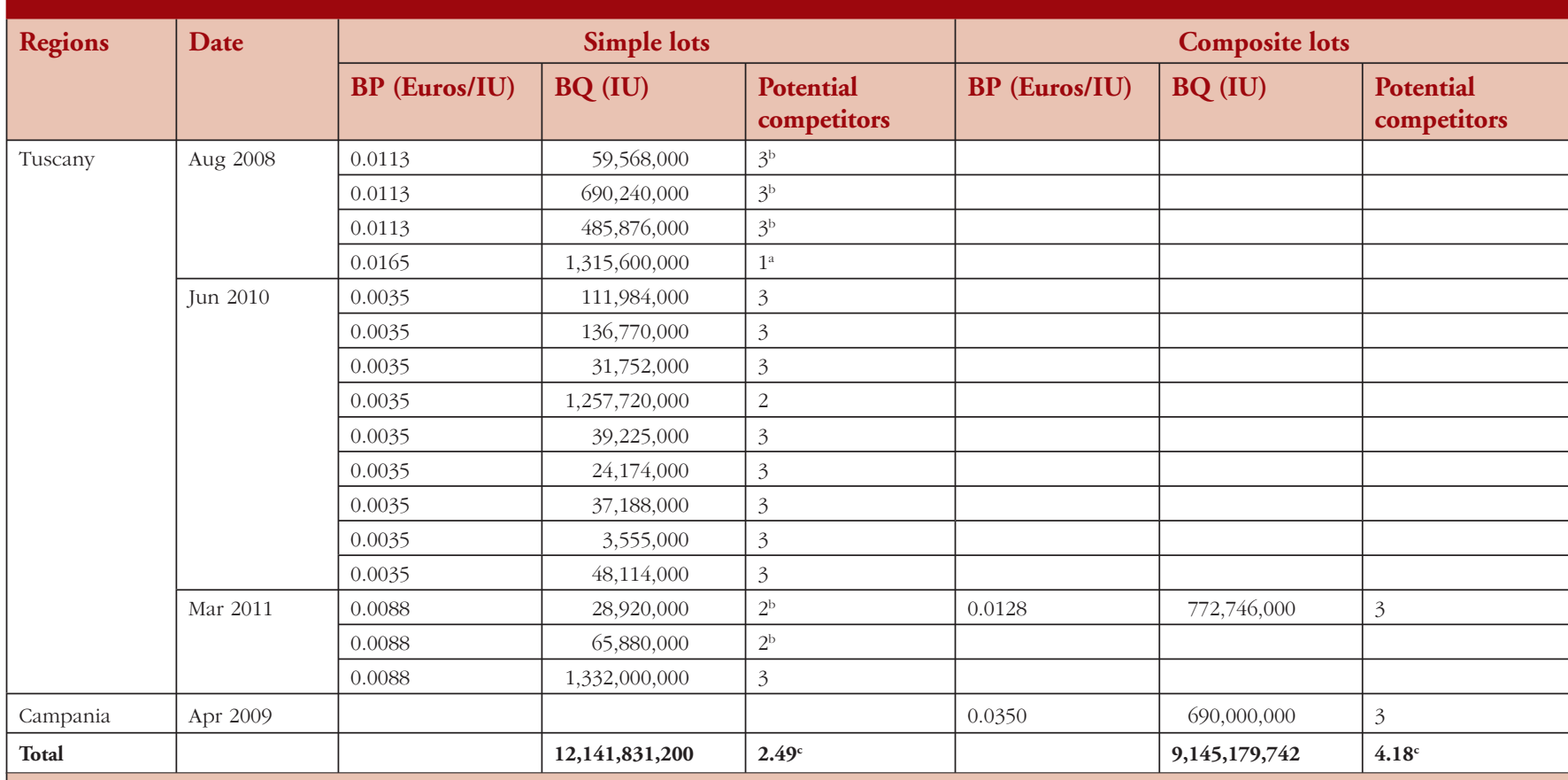

c) Filgrastim (16 lots)

\begin{tabular}{|c|c|c|c|c|}
\hline \multirow[t]{2}{*}{ Regions } & \multirow[t]{2}{*}{ Date } & \multicolumn{3}{|c|}{ Simple lots } \\
\hline & & BP (Euros/MIU) & BQ (MIU) & Potential competitors \\
\hline Lombardy & Aug 2010 & 1.51 & $3,337,500$ & 5 \\
\hline Piedmont & Jun 2011 & 1.94 & $1,084,500$ & 5 \\
\hline Emilia-Romagna & Apr 2011 & 0.97 & $4,320,000$ & 5 \\
\hline \multirow[t]{5}{*}{ Friuli-Venezia Giulia } & Dec 2009 & 3.88 & 313,500 & $1^{\mathrm{a}}$ \\
\hline & \multirow{2}{*}{ Apr 2010} & 3.88 & 39,000 & $1^{\mathrm{a}}$ \\
\hline & & 3.88 & 18,000 & $4^{\mathrm{b}}$ \\
\hline & Mar 2011 & 3.02 & 150,000 & $1^{\mathrm{a}}$ \\
\hline & Mar 2012 & 1.83 & 66,180 & $1^{\mathrm{a}}$ \\
\hline Veneto & Oct 2012 & 0.29 & $2,753,820$ & 5 \\
\hline \multirow[t]{5}{*}{ Tuscany } & \multirow[t]{2}{*}{ Mar 2010} & 3.20 & 516,000 & 5 \\
\hline & & 4.27 & 14,400 & $1^{\mathrm{a}}$ \\
\hline & Jun 2010 & 1.80 & 142,650 & 5 \\
\hline & \multirow[t]{2}{*}{ Mar 2011} & 3.02 & 610,200 & 5 \\
\hline & & 2.91 & 67,680 & $3^{b}$ \\
\hline \multirow[t]{2}{*}{ Campania } & Feb 2010 & 2.04 & $1,101,720$ & 5 \\
\hline & Dec 2011 & 1.92 & 6,000 & $1^{\mathrm{b}}$ \\
\hline Total & & & $14,541,150$ & $4.29^{c}$ \\
\hline
\end{tabular}

\section{Discussion}

The main limitation of our survey is that it relied on information retrieved from the Internet. Especially in regions with less modern IT systems or complex interfaces, we may have missed some documents. However, we opted for this tool since all acts and administrative measures from Italian public authorities have had to be published online since January 2011 (Law 69/2009). Another major intrinsic limit is the lack of awarded prices in the analysis, as not all prices were available on the Internet. To our knowledge, however, this study is the first to describe the main characteristics of public tenders for procuring off-patent biologicals at hospitals in Italy, and indeed in Europe.

In general, the prevailing practice in Italy is to launch very large tenders divided into many lots. Most of the 191 lots referring to the three off-patent biologicals were 'simple type', potentially less open to competition than composite lots. Competition was further limited, as there was only one potential competitor for 
many lots, due to the strict requirements for each lot. The need to continue a therapy that had already started, according to the current non-substitution policy, may explain the substantial number of lots restricted to original agents (around 30\%), while fewer lots were restricted to biosimilars (around 13\%), which may have been aimed at enhancing their market success, and preserving them from aggressive under-pricing by the original agent which could become an insurmountable barrier for their wider use.

Nevertheless, the lack of potential competition, particularly for somatropin, seems to be extensive and hard to justify in Italian regional tenders. Although it was the first biological patent to expire, somatropin has just one biosimilar marketed and the least overlap of packages available among the licensed products, most lots referring to single dosages. The potential level of competition was higher for epoetin and filgrastim tenders. Both have three biosimilars marketed and more overlap of dosages. Epoetin was the only biological for which composite lots were tendered, a type of lot that should foster more competition in theory. Filgrastim was the only biological for which we found some relation between base price and base quantity, and base price decreased over time too, a trend which should support the hypothesis that awarded prices declined as well.

In theory, worthwhile savings may be achieved from tenders [10]. However, in practice this depends on how the bidders (manufacturers) and buyers (regional authorities) behave in the market. What happens in the Italian regional tenders on off-patent

\section{Figure 2: Correlation between base price (BP), base quantity (BQ)} and time
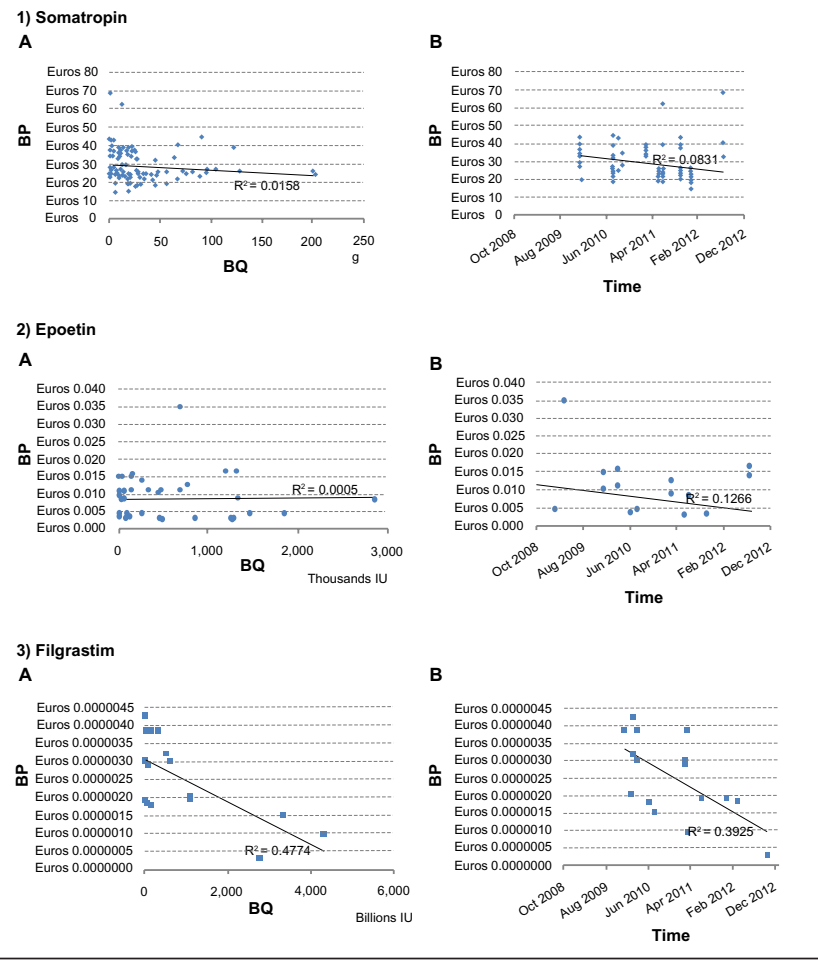

biologicals does not seem to foster much competition. From the supply side, central authorities have allowed manufacturers to launch several packages with different dosages and forms, in order to differentiate their products from one another. On the demand side, regional authorities do not seem to exploit their purchasing power to the full by tendering many piecemeal lots that are restricted to only one product. This behaviour, which might stem from concern about legal litigation with 'losers of tenders' (this has happened quite frequently in Italy [11]) seems mainly to favour the marketing strategies of pharmaceutical companies, rather than generating potential savings for the NHS.

\section{Competing interests: None.}

Provenance and peer review: Not commissioned; externally peer reviewed.

\section{Authors}

Alessandro Curto, MSSc

Katelijne Van de Vooren, MSc

Roberta Lo Muto, MSc

Silvy Duranti, MBA

Professor Livio Garattini

Centre for Health Economics (CESAV), Istituto di Ricerche Farmacologiche Mario Negri (IRCCS), IT-24020 Ranica (BG), Italy

\section{References}

1. The European Federation of Pharmaceutical Industries Associations 2011. The Pharmaceutical Industry in Figures. [cited 2013 May 27]. Available from: http://www. efpia.eu/uploads/Modules/Documents/figures_2011_final-20110610-014-en-v1.pdf

2. Garattini L, Van de Vooren K, Curto A. Pricing human papillomavirus vaccines lessons from Italy. Pharmacoeconomics. 2012;30(3):213-7.

3. National Institute of Statistics, Italy. Available from: http://demo.istat.it/ index_e.html

4. Casadei G. Biosimilari in rapida evoluzione? Quaderni di Farmacoeconomia. 2011;16:21-9.

5. De Belvis AG, Ferrè F, Specchia ML, Valerio L, Fattore G, Ricciardi W. The financial crisis in Italy: implications for the healthcare sector. Health Policy. 2012;106(1):10-6.

6. Haustein R, et al. Saving money in the European healthcare systems with biosimilars. Generics and Biosimilars Initiative Journal (GaBI Journal). 2012;1(3-4).120-6. doi:10.5639/gabij.2012.0103-4.036

7. Rovira J, et al. Biosimilars in the European market. Generics and Biosimilars Initiative Journal (GaBI Journal). 2013;2(1):30-5. doi:10.5639/gabij.2013.0201.012

8. Aapro M. Biosimilars in oncology: current and future perspectives. Generics and Biosimilars Initiative Journal (GaBI Journal). 2013;2(2):39-42. doi:10.5639/ gabij.2013.0202.023

9. TED (Tenders Electronic Daily). Supplement to the Official Journal of the European Union. [cited 2013 May 27]. Available from: http://ted.europa.eu/ TED/main/HomePage.do

10. Laffont, JJ, Tirole, J. Auctioning incentive contracts. Journal of Political Economy. 1987;95(5):921-37.

11. Cassamagnaghi S, Miani V. Farmaci biosimilari: l'approvvigionamento delle P.A. e l'equivalenza terapeutica "ponderata". Sole24ore. 2013 Jan 14. [cited 2013 May 27]. Available from: http://www.diritto24.ilsole24ore.com/avvocatoAffari/ mercatiImpresa/2012/06/farmaci-biosimilari-lapprovvigionamento-da-partedelle-pa-e-lequivalenza-terapeutica-ponderata.html

DOI: 10.5639/gabij.2013.0203.036

Copyright (c) 2013 Pro Pharma Communications International 